\title{
Measuring the Contribution and Complexity of Nurse and Physiotherapy Consultants: A Feasibility Study
}

\author{
Janet Richardson ${ }^{*}$, , Roberta Ainsworth ${ }^{2}$, Ann Humphreys $^{3}$, Elizabeth Stenhouse ${ }^{4}$ and Mary Watkins ${ }^{5}$ \\ ${ }^{I}$ Faculty of Health and Social Work, University of Plymouth, Drake Circus, Plymouth PL4 8AA, UK \\ ${ }^{2}$ Torbay Hospital, Torquay, Devon TQ2 7AA, UK \\ ${ }^{3}$ Faculty of Health and Social Work, University of Plymouth, Drake Circus, Plymouth PLA 8AA, UK \\ ${ }^{4}$ FF20, Peninsula Allied Health Centre, School of Health Professions, UK \\ ${ }^{5}$ University of Plymouth, Drake Circus, Plymouth PL4 8AA, UK
}

\begin{abstract}
Advanced practice roles in nursing and other health professions have become integral to a range of healthcare services world-wide providing experienced practitioners with the opportunity to extend their roles and influence decision making whilst maintaining patient contact. However, there has been limited research to evaluate the impact on health services of these advanced practice roles.

The aim of this feasibility study was to analyse Nurse and Allied Health Professionals (AHP) Consultant activity in the four functions of the role (education, expert practice, leadership, research). A structured diary assessed the activity of five Consultant Nurses and one Consultant Physiotherapist over a one week period. Detailed analysis of a clinic carried out by one of the Consultants was undertaken using a mapping procedure.
\end{abstract}

Results suggest that the activity diary, combined with mapping of activities, illustrate the complexity and variety of the role and facilitate meaningful reflection on what advanced practitioners do.

Keywords: Nurse, midwife, physiotherapist, consultant, effectiveness.

\section{INTRODUCTION}

Advanced practice roles in nursing and Allied Health Professions (AHP) have become integral to a range of healthcare services world-wide. Roles are diverse, and attempts are being made to adopt a common identity [1]). The two factors that appear to be common to all advanced practice roles: high education level (masters and doctoral degrees) and independent practice.

The introduction of the Consultant role in Nursing and the AHPs in the UK provided experienced practitioners with the opportunity to extend their roles and influence decision making at a strategic level whilst maintaining patient contact. The four key functions of the Consultant role are: expert practice, leadership, education and research, and have been highlighted in policy documents as four functions that must be evident in all posts.

Nurse and AHP Consultant posts have been linked to specific clinical pathways or National Service Frameworks such as stroke, cancer care and mental health, or introduced into a specific area of practice such as Accident and Emergency [2]. The Consultant posts are autonomous, having the freedom and authority to act independently in order to lead and develop clinical practice $[3,4]$. Working in this way

*Address correspondence to this author at the Faculty of Health and Social Work, Room C502 Portland Square, University of Plymouth, Drake Circus, Plymouth Devon PL4 8AA, UK; Tel: 01752 233872;

E-mail: janet.richardson@plymouth.ac.uk could provide opportunities for healthcare practitioners to influence service developments at a strategic level, be involved in inter-professional team working and help break down the traditional hierarchies often seen within healthcare. However, a number of challenges have been reported when staff take on these roles. For example: role clarity, unreal expectations of what one person can do, preparation for and fitness for practice once in role, lack of systematic planning or policy implementation at a local level and organisational factors such as the development of a supportive workplace [2,5-8].

The first generation of Nurse and AHP Consultants have now been in post for approximately 6-7 years, and have applied their roles in an innovative ways. For example to devise training schemes to help nurses to identify aspects of care which patients find most useful [9]. However finding evidence to support the effectiveness of Consultant roles is a challenge due to the small number of studies available [10]. Studies have considered, for example, the effectiveness of Nurse Consultants in the UK [11,12], factors influencing higher level of practice [13], how Nurse Consultants work alongside others [14], and how they use the role in the context of leadership and change agent in practice [15-17]. However, studies examining the effectiveness of AHP Consultants are limited [18].

Many of the large scale, quantitative examinations of the activity of nurses in traditional roles have focused on skillmix and tasks $[19,20]$. In contrast, attempts to evaluate the activity and impact of Nurse Consultants have concentrated 
on Consultant perceptions,_and failed to provide supporting data on what Consultants actually do [21]). This is evidenced by the work of Guest and Coster et al. [22,23] who used a self-administered questionnaire and asked participants to rate their involvement in activities associated with the Consultant role using a Likert-type scale. Analysis of the data provided mean scores and the results were presented as levels of involvement in the specific activities, eight management activities and the four functions of the Consultant role. Structured diaries were one of the data collection tools used in Unsworth and Cook's study [24]; the information collected over a four-week period was very detailed and included recording each activity undertaken, an activity description form, any involvement of others and whether it was a 'oneoff' episode or a regular occurrence. Unfortunately analysis of the diaries was not fully documented.

The strength of diaries as a data collection tool is that they can be structured or unstructured, provide first hand reporting of a situation and can generate large amounts of data [25-27]). However, the limitations include poor compliance of the participant and the incompleteness of the recording [24]. There are a number of examples of the use of structured and unstructured diaries in health care research to record the experiences of patients. These include older people living with chronic health problems [28]; health and wellbeing in families in rural Australia [29] and use of a diary to record near misses and minor injuries [30].

There is evidence that structured, semi-structured diaries or activity $\operatorname{logs}$ have been used in multi-method studies to examine the work of health care staff. Examples include the work of Macmillan Nurses in two care settings [31]; a time and motion study of psychiatric clinical nurse specialists in North America [32] and measurement of the time spent on patient care by specialist palliative care nurses in Germany [33]. Time sampling involves the participant recording their activity at designated times [34]. Robson [26] describes this as 'interval sampling'. In 'event sampling' the trigger for recording is the occurrence of a pre determined activity. This approach is chosen when the occurrence is infrequent, eliminating the risk that data could be incomplete [25,34].

Given the lack of evidence about the impact and effectiveness of these relatively new advanced practitioner roles, it is important to understand what Consultants do by assessing their activity.

\section{AIM}

The aim of this study was to carry out an analysis of current Nurse and AHP Consultant activity and examine this activity in the context of the four functions of the role (education, expert practice, leadership, and research).

\section{OBJECTIVES}

1. To construct, pilot and test a diary to collect data on Consultant activity.

2. To analyse Consultant activity in relation to the four functions of the role.

3. To assess role complexity using an example of one Consultant session.

\section{METHODS}

A mixed-method approach was used: discussions with Consultants provide the qualitative data used to construct the activity diary; activities were recorded in time-units enabling quantitative analysis of activities related to key functions of the role; situation analysis provided a contextual explanation and pictorial representation of an example of activity during a specific time-frame.

To examine the tasks undertaken by the Consultants, a structured activity diary was selected in order to use an 'interval sampling' approach. This allowed each Consultant to record items of activities throughout their working week. These activities could be analysed according to the four functions of the role. The length of the interval between activity recording has to be a 'psychologically meaningful time frame' according to [34] otherwise compliance may be compromised. Sampling at fifteen minute intervals was selected because it is not too long to affect recall and not too demanding on time. This sampling allowed for the recording of more than one of the activities simultaneously in a fifteen minute period.

\section{Participants}

A purposive sample of 6 Consultants (5 Nurse Consultants and 1 Physiotherapy Consultant) employed in a specific region within the UK (the region providing sponsorship for the study) were invited to take part in the study. Selection criteria:

- $\quad$ Representation for the whole of the region providing sponsorship

- Representative of the number of professionals in Consultant roles (at the time of the study there were no Midwife Consultants in post)

- Representative of the range of specialisms: mental health, primary care, acute care

- In a Consultant post at least 2 years

- Must have a supporting 'sponsor' in the form of Nurse / AHP manger

\section{Data Collection}

Guided discussions with the Consultants were undertaken in order to establish a detailed understanding of activities they perform on a daily basis. Subsequent thematic analysis identified independent activities within the Consultant role. These activities were given a numerical code and classified under the four functions and used to construct the activity diary (Table 1.).

The Consultants were asked to comment on the classification of the activities and two of the Consultants piloted the activity diary for one day. Following feedback from the pilot relevant amendments were made. From the pilot it was clear that activities such as travel and administration could be related to any of the four functions of the role, hence the duplication of these activities in the activity diary. Data collection involved two stages. Stage one involved collecting data using the activity diaries in order to build the 'rich picture' to inform the situation analysis in stage two. The activity 
Table 1. Activity Codes

\begin{tabular}{|c|c|c|c|c|}
\hline Activity Type & Expert Practice & Leadership & Education & Research \\
\hline \multirow[t]{15}{*}{ Specific Activity: } & $\begin{array}{l}1 \text { Dealing with complex } \\
\text { cases }\end{array}$ & 19 Board-level input & 37 Conference presentation & 49 Carrying out an audit \\
\hline & $\begin{array}{l}2 \text { Development of own } \\
\text { practice } \\
\text { (e.g. on a course, learn- } \\
\text { ing a skill) }\end{array}$ & 20 Development of other staff & $\begin{array}{l}38 \text { Facilitating learning in } \\
\text { clinical environment }\end{array}$ & $\begin{array}{l}50 \text { Accessing research for } \\
\text { practice }\end{array}$ \\
\hline & 3 Giving advice & $\begin{array}{l}21 \text { Facilitating the multi- } \\
\text { disciplinary team }\end{array}$ & $\begin{array}{l}39 \text { Formal teaching in the } \\
\text { Trust }\end{array}$ & $\begin{array}{l}51 \text { Evaluating a service devel- } \\
\text { opment }\end{array}$ \\
\hline & 4 Making diagnosis & $\begin{array}{l}22 \text { Implementing a service } \\
\text { development }\end{array}$ & $\begin{array}{l}40 \text { Formal teaching in the } \\
\text { University }\end{array}$ & 52 Data collection \\
\hline & 5 Planning care & 23 Line management of staff & $\begin{array}{l}41 \text { Planning educational pro- } \\
\text { grammes }\end{array}$ & 53 Data analysis \\
\hline & $\begin{array}{l}6 \text { Prescribing medica- } \\
\text { tion }\end{array}$ & 24 Mentoring staff & $\begin{array}{l}42 \text { Preparing teaching for } \\
\text { Trust }\end{array}$ & 54 Planning research \\
\hline & $\begin{array}{l}7 \text { Requesting diagnostic } \\
\text { tests }\end{array}$ & 25 National level input & $\begin{array}{l}43 \text { Preparing teaching for } \\
\text { University }\end{array}$ & $\begin{array}{l}55 \text { Research ethics (applying } \\
\text { or committee matters) }\end{array}$ \\
\hline & 8 Referral to medic & $\begin{array}{l}26 \text { Providing medical consult- } \\
\text { ant cover }\end{array}$ & 44 Travel & 56 Research presentation \\
\hline & $\begin{array}{l}9 \text { Referral to other } \\
\text { professional }\end{array}$ & $\begin{array}{l}27 \text { Planning a service devel- } \\
\text { opment }\end{array}$ & 45 Administration & 57 Travel \\
\hline & $\begin{array}{l}10 \text { Providing a special- } \\
\text { ist intervention (eg } \\
\text { injection) }\end{array}$ & 28 Strategic planning & & 58 Administration \\
\hline & 11 Case Assessment & $\begin{array}{l}29 \text { Managing Clinical Super- } \\
\text { vision }\end{array}$ & & \\
\hline & 12 Group Session Care & 30 Chairing Meeting & & \\
\hline & $\begin{array}{l}13 \text { Critical Care analy- } \\
\text { sis }\end{array}$ & $\begin{array}{l}31 \text { Supervising Implementa- } \\
\text { tion of Nursing Guidelines }\end{array}$ & & \\
\hline & 14 Travel & 32 Travel & & \\
\hline & 15 Administration & 33 Administration & & \\
\hline \multirow{3}{*}{$\begin{array}{l}\text { If other code used } \\
\text { please specify activity }\end{array}$} & 16 Other & 34 Other & 46 Other & 59 Other \\
\hline & 17 Other & 35 Other & 47 Other & 60 Other \\
\hline & 18 Other & 36 Other & 48 Other & 61 Other \\
\hline
\end{tabular}

diaries were distributed to each participating Consultant $(\mathrm{N}=6)$. They were requested to complete the activity diary for a 7-day period commencing Monday $00.01 \mathrm{hrs}$ until Sunday $2359 \mathrm{hrs}$ in a designated week. Contact details of the members of the project team were available to answer queries related to the study. Completed diaries were returned to the research team for analysis. Activities were recorded as codes for each 15 minute time-interval in order that the amount of time spent on each activity could be calculated.

The situation analysis (Stage 2.) involved examining multiple coding (i.e. a number of activities recorded within a single time-frame) using a Soft Systems Methodology (SSM) mapping procedure in order to help to identify concurrent themes. This was accompanied by a summary of the activity under investigation during this time-interval and was based on the Consultant's clinic notes. SSM is used to analyse situations that are ill-defined, unstructured, or complex. Although the model has seven stages, it was only appropriate to apply the first two stages to the data in the current study.

\section{Data Analysis}

Two members of the project team examined the completed diaries for obvious violations and errors independently and collectively. Activity codes were single entered onto a database by each time event (15 minute units), a maximum of four activity codes had been recorded for each time unit. Other members of the project team examined the data for errors and inconstancies as a review of the accuracy and consistency of data entry. Queries were highlighted and discussed with the project team, rechecked against the original and if required re entered. Results are presented as total number of hours and percentages.

\section{RESULTS}

\section{Consultant Activity}

Six Consultants completed a diary for the 7 day study period. Collectively the Consultants worked 330.15hours per week, a mean of 55hours during the seven-day study period (Table 2). 
Table 2. Number of Hours Worked by Consultants by Day

\begin{tabular}{|c|c|c|c|c|c|c|c|}
\hline Consultant & Monday & Tuesday & Wednesday & Thursday & Friday & Saturday & Sunday \\
\hline \hline 1 & 1230 & 12.15 & 12.30 & 12.30 & 12.30 & 1.30 & 1.30 \\
\hline 2 & 13.45 & 11.15 & 8.30 & 8.30 & 8.30 & 0.00 & 3.30 \\
\hline 3 & 12.15 & 11.15 & 11.30 & 11.45 & 11.45 & 4.45 & 6.00 \\
\hline 4 & 9.15 & 8.15 & 10.15 & 9.00 & 8.00 & 0.00 & 0.00 \\
\hline 5 & 10.45 & 10.15 & 12.00 & 10.45 & 8.15 & 0.00 & 4.00 \\
\hline 6 & 8.30 & 9.15 & 8.30 & 8.00 & 5.15 & 0.00 & 0.00 \\
\hline
\end{tabular}

Extensive analysis was undertaken to estimate the proportion of time spent on the four functions, and activity undertaken within each function. Patterns of work in terms of activities and hours worked were very different for each Consultant. However, it was clear from the data that expert practice was afforded the highest priority in terms of time spent on this aspect of the role (Fig. 1).

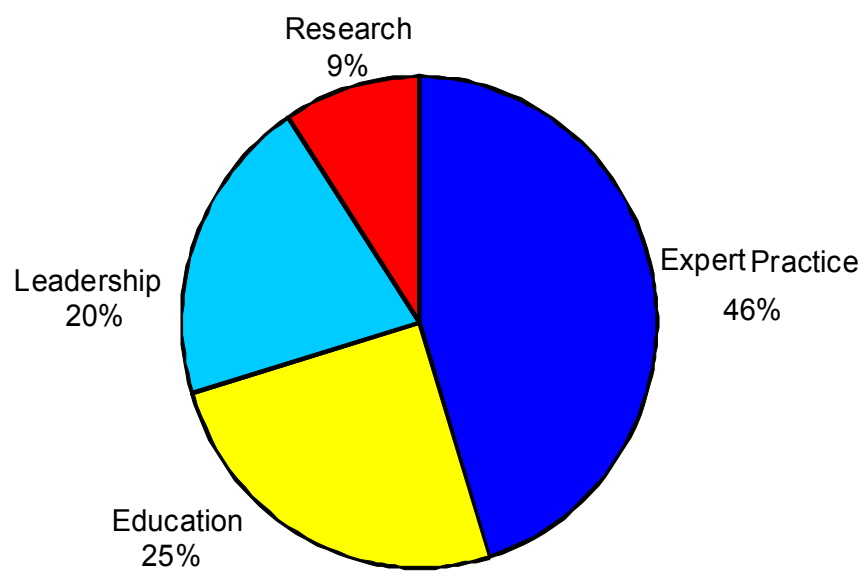

Fig. (1). Percentage of week worked within each pillar for all consultants.
The diversity of the role could also be seen in different working patterns on different working days (Table 3 ).

Fig. (2) provides an example of expert practice activity for one Consultant on one day.

\section{Situation Analysis}

Several Consultants demonstrated multitasking within a 15 minute time event evidenced by multiple coding. Therefore in order to provide an example of how this multiple coding related to the four key functions of the role one clinical setting was examined in more detail using a situation analysis and mapping procedure. The Consultant Physiotherapist provided this example as she had more extensive multiple coding of activities than the other Consultants. Based on the Soft Systems Methodology. Fig. (3) shows the interrelationship of tasks within and between role functions, and is based on multiple coding by the Physiotherapy Consultant during an outreach teaching clinic. The numbers in the circles relate to the relevant activity code as detailed in Table $\mathbf{1}$.

Details of the context based on this Consultant's clinic notes are provided in Box 1. The Consultant had established a teaching shoulder clinics as a service development in order to combine the clinical expert element of the Consultant post with education and leadership. Referrals were made by medical consultants, general practitioners and other physio-

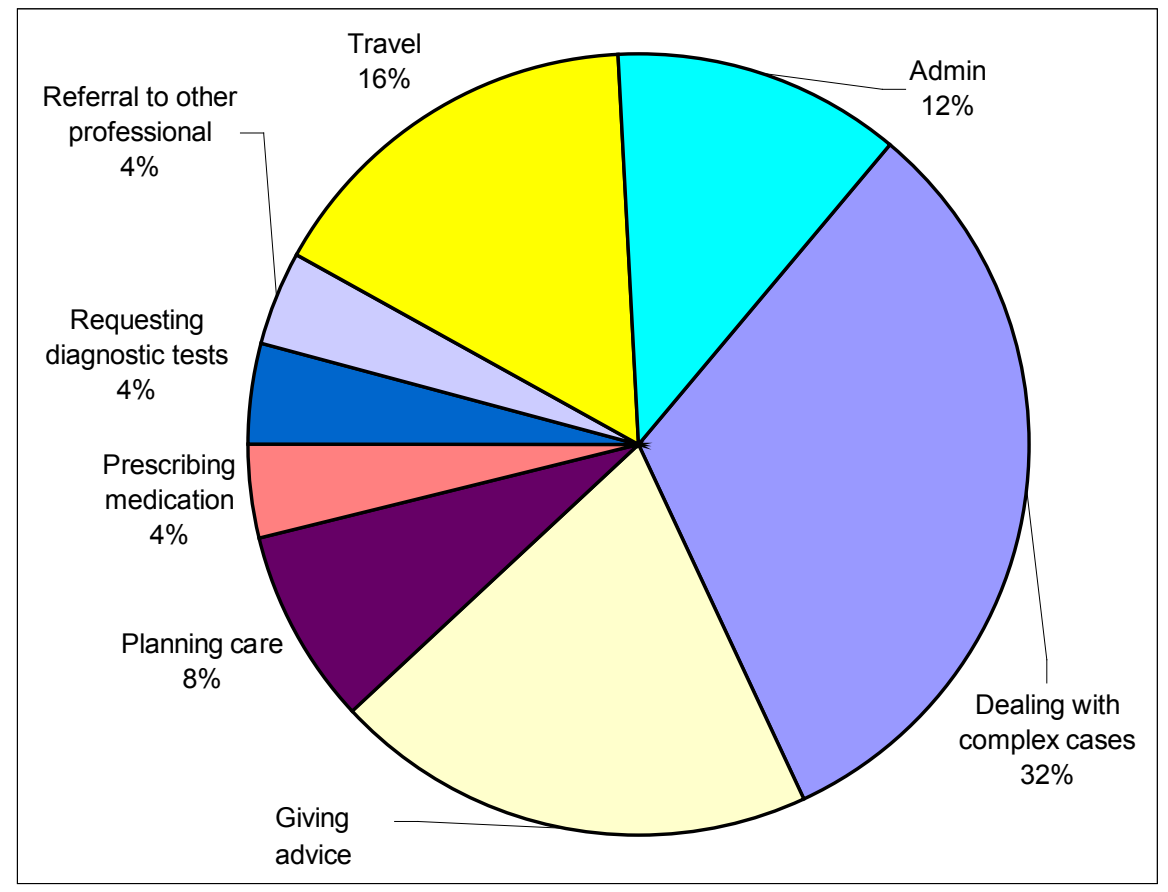

Fig. (2). Expert practice activity for consultant nurse 2 on Monday. 
Table 3. Number of Hours Worked Within Each Pillar for Consultant Nurse 5

\begin{tabular}{|l|c|c|c|c|}
\hline & Expert Practice & Leadership & Education & Research \\
\hline \hline Monday & $3 \mathrm{hrs} 15 \mathrm{mins}$ & $2 \mathrm{hrs} 45 \mathrm{mins}$ & $4 \mathrm{hrs} 00 \mathrm{mins}$ & $1 \mathrm{hr} 00 \mathrm{mins}$ \\
\hline Tuesday & $4 \mathrm{hrs} 15 \mathrm{mins}$ & $2 \mathrm{hrs} 45 \mathrm{mins}$ & & $1 \mathrm{hr} 30 \mathrm{mins}$ \\
\hline Wednesday & $9 \mathrm{hrs} 00 \mathrm{mins}$ & $2 \mathrm{hrs} 00 \mathrm{mins}$ & & \\
\hline Thursday & $5 \mathrm{hrs} 15 \mathrm{mins}$ & $4 \mathrm{hrs} 45 \mathrm{mins}$ & $2 \mathrm{hrs} 30 \mathrm{mins}$ & \\
\hline Friday & $6 \mathrm{hrs} 45 \mathrm{mins}$ & & & $1 \mathrm{hr} 00 \mathrm{mins}$ \\
\hline Saturday & & & & $3 \mathrm{hrs} 00 \mathrm{mins}$ \\
\hline Sunday & & & & $\mathrm{hr} 00 \mathrm{mins}$ \\
\hline
\end{tabular}

therapists, and are predominantly patients with a complex presentation, those whose physiotherapy treatment had been unsuccessful, or whose diagnosis was uncertain.

Three clinics run simultaneously with physiotherapists of varying experience conducting each clinic, with the Consultant Physiotherapist working across the clinics using her expertise to support diagnosis, intervention and decision-making. The tasks undertaken by the Consultant Physiotherapist alone include giving steroid injections into affected joints, requesting $\mathrm{X}$-rays and ultra sound scans and placing patients requiring specific procedures directly onto the surgical waiting list.

\section{DISCUSSION}

The activity diary appeared to be a useful tool for examining what Nurse and AHP Consultants actually do during the course of their daily work. However, the complexity of the role and the inter-relationship of these activities were not captured by the activity analysis alone. The detailed examination of a clinic example using the Consultant Physiotherapist's clinic notes, together with the activity analysis and subsequent 'mapping' procedure, provided further detail about what was actually taking place in the clinic when multiple activity codes were entered into the diary. Analysis of this multiple coding suggests that within a 15 minute time event, Consultants have the capacity to integrate four functions of their role simultaneously. This is an aspect of Consultant work not previously captured, and begins to explore the complexity and diversity of the role and potential for the Consultant to role model different aspects of advanced practice simultaneously. Measurement of activity provides a more accurate assessment of Consultant roles than measures

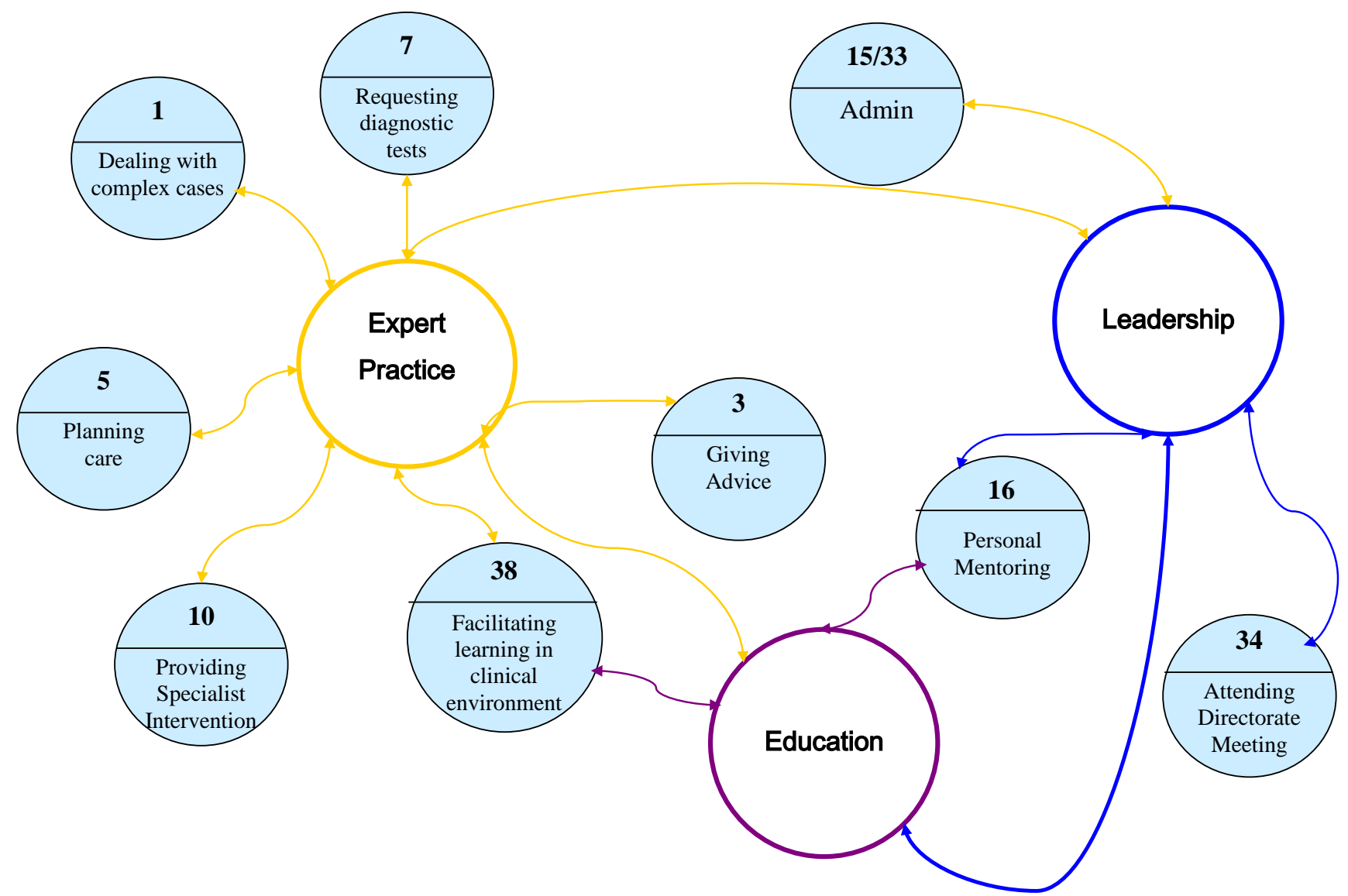

Fig. (3). Multiple coding for consultant physiotherapist (outreach teaching clinic 8.30am-12md). 


\section{Box 1. Context of Situation Analysis Based on Clinic Notes}

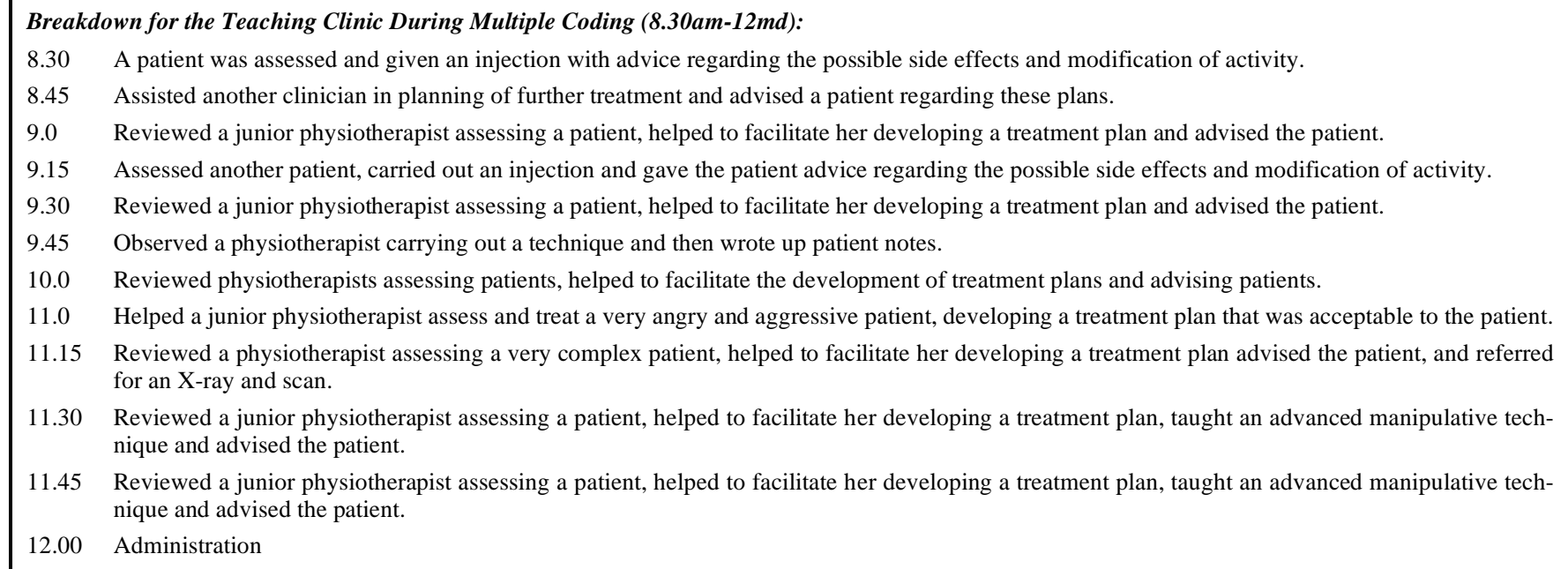

of perception of activity. Multiple coding reflects the complexity of the role and the extent to which the different functions overlap and are undertaken simultaneously. This supports previous studies that highlight the complexity and diversity of the Consultant role [21]). Coster et al. [23]) found that the greater the number of activities Consultants reported being engaged in, the higher they rated the impact they had on their service. The current study has demonstrated how Consultants undertake multiple activities in the context of expert practice, and how these activities overlap with other functions, for example education and leadership. Although Consultant roles, by their very nature are diverse, developing an understanding of what Consultants do and how what they do impacts on patient outcomes is essential for the sustainability of the role.

This feasibility has a number of weaknesses that require attention prior to conducting a larger study of Nurse and AHP Consultant activity. Multiple coding of activities produced a number of codes within individual time-units, thus providing an analytical challenge. For example the pie charts developed in order to illustrate activity only reflected one element (code). Furthermore, not all of the Consultants used multiple coding in their activity diaries. Failure to code multiple activities within a time-unit may have been due to the instructions on the diary as it was not explicit that multiple coding was an option. Thus Consultants may have underreported activity. Additionally, the different categories of administration carried different codes which added to the complexity and was possibly unnecessary. This was only a snapshot of a one week period, and pertinent elements of the job may well have been omitted as none of the consultants was able to identify a "standard" week. Furthermore, the method relied on the Consultants recording their own activities rather than an independent observation of what they were doing. However, the activity diary and subsequent mapping of activities clearly provides a useful tool for assessing Consultant activity.

While the results may not be generalisable to other Consultants, the methods could be applied to different settings and used to compare and contrast advanced practitioner roles. The strength of the methods used in this study lie in the ability to reflect the complexity and variety of the role, and provides an opportunity for comparisons between disciplines. Further research should also assess the activities in relation to measures of impact, for example patient outcomes and skills development in other staff.

\section{ACKNOWLEDGEMENTS}

The study was commissioned by the South West Peninsula Strategic Health Authority and Plymouth Teaching Primary Care Trust.

\section{REFERENCES}

[1] MacDonald JA, Herbert R, Thibeault C. Advanced practice nursing: unification though a common identity. J Prof Nurs 2006; 22(3): 172-9

[2] McSherry R, Johnson SC. Demystifying the Nurse/Therapist Consultant: a foundation text. Nelson Thornes, Cheltenham, 2005.

[3] Kelly LY, Joet LA. Dimensions of Professional Nursing. $7^{\text {th }}$ Edition, McGraw Hill, London, 1995.

[4] Creasia LJ, Parker B. Conceptual Foundations of Professional Nursing Practice. Mosby, London, 1996.

[5] Adams A, Pelletier D, Nagy S. Determining and discerning expert practice: a review of the literature. Clin Nurse Spec 1997; 11, $217-$ 222.

[6] Nurse Practitioner UK. What is a Nurse Practitioner: Your questions answered, 1999.

[7] Sneed NV. Power: its use and potential for misuse by nurse consultants. Clin Nurse Spec 1991; 5: 58-62.

[8] Wilson-Barnett J. A Preliminary Evaluation of the Establishment of Nurse, Midwife and Health Visitor Consultants. Florence Nightingale School of Nursing and Midwifery, King's College, London, 2003.

[9] Sandford R. I call it the rock and roll of nursing. Nurs Times 2004; 100(31): 28-9.

[10] Lynch MP, Cope DG, Murphy-Ende K. Advanced practice issues: results of the ONS Advanced Practice Nursing survey. Oncol Nurs Forum 2001; 28(10): 1521-30.

[11] Bent J. How effective and valued are nurse consultants in the UK? Nurs Times 2004; 100: 34-36.

[12] Watkinson M. The impact of the diabetes nurse consultant. J Diabet Nurs 2004; 8: (3) 84.

[13] Fairley D. Nurse consultants as higher level practitioners: factors perceived to influence role implementation and development in critical care. Intensive Crit Care Nurs 2003; 19: 198-206.

[14] Dewing J, Reid B. A model for clinical practice within the consultant nurse role. Nurs Times 2003; 99: 30-32.

[15] Haines C. The establishment of a nurse consultant role in paediatric intensive care: a reflective analysis. Nurs Crit Care 2002; 7: 73-83.

[16] Manley K. Organisational cultural and consultant nurse outcomes: Part 1. Organisational culture. Nurs Stand 2000; 14(36): 34-38. 
[17] Manley K. Organisational cultural and consultant nurse outcomes: Part 2. Nurse outcomes. Nurs Stand 2000; 14(37): 34-39.

[18] Humphreys A, Johnson S, Richardson J, Stenhouse E, Watkins M. A systematic review and meta-synthesis: evaluating the effectiveness of nurse, midwife / allied health professional consultants. J Clin Nurs 2007; 16: 1792-1808.

[19] Buchan J, Ball J. Caring Costs. Nursing Costs and Benefits. A Review for the Royal College of Nursing. Institute of Manpower Studies Report No. 208. University of Sussex, Brighton, 1991.

[20] Audit Commission. The Virtue of Patients: Making the best use of Nursing Resources. HMSO, London 1991.

[21] Lathlean J. Researching the implementation of pioneering roles in nursing and midwifery: Empirical insights about lecturer practitioners, consultant nurses and nurse registrars. J Res Nurs 2007; 12(1): 29-39.

[22] Guest D, Peccei R, Rosenthal P, et al. An Evaluation of the Impact of Nurse. Midwife and Health Visitor Consultants. Kings College London (unpublished report), 2004

[23] Coster S, Redfern S, Wilson-Barnet J, Evans A, Peccei R, Guest S. Impact of the role of nurse, midwife and health visitor consultant. J Adv Nurs 2006; 55(3): 352-363.

[24] Unsworth J, Cook G. The impact of nurse consultants on clinical practice: an evaluation. Unpublished report, Northumbria University Primary Care Development Centre, Northumbria, 2003.

[25] Burgess L. In the field: an introduction to field research. Routledge London, 1990
[26]

Robson C. Real World Research. A Resource for Social Scientists and Practitioner-Researchers. Blackwell Publishers Ltd, Oxford, 1993.

[27] Gibson V. An analysis of the use of diaries as a data collection instrument. Nurse Res 1995; 3(1): 66-73.

[28] Jacelon C, Imperio K. Participant Diaries as a Source of Data in Research with Older Adults. Qual Health Res 2005; 17(7): 991-997

[29] Keleher H, Verrinder G. Health diaries in a rural Australian study. Qual Health Res 2003; 13(3): 435-443

[30] Marsh P, Kendrick D. Using a diary to record neat misses and minor injuries-which method of administration is best? Inj Prev 1999; 5: 305-309.

[31] Skilbeck J, Seymour J. Meeting complex needs: an analysis of Macmillan nurses' work with patients. Int J Palliat Nurs 2002; 8(12): 574-582

[32] Glick H, Kinosian B, McBride L, Williford WO, Bauer M. Clinical nursing specialist care managers' time commitments in a diseasemanagement program for bipolar disorder. Bipolar Disord 2004; 6: 452.

[33] Weber M, Grohmann L. Time expenditure in patient-related care provided by specialist palliative care nurses in a community hospice service. Palliat Med 2004; 18: 719-726.

[34] Polit D, Hungler B. Nursing Research-Principles and Methods. Fourth Edition. J.D. Lippincott Company, Philadelphia, 1991.

This is an open access article licensed under the terms of the Creative Commons Attribution Non-Commercial License (http://creativecommons.org/licenses/by$\mathrm{nc} / 3.0 /$ ) which permits unrestricted, non-commercial use, distribution and reproduction in any medium, provided the work is properly cited. 